\title{
Harmonising, improving and using social and recreational data in National Forest Inventories across Europe
}

\author{
Mark A. Atkinson ${ }^{1} \cdot$ David M. Edwards ${ }^{1}$ • Frank Søndergaard Jensen ${ }^{2} \cdot$ Alexander P. N. van der Jagt $^{1,3}$. \\ Ben R. Ditchburn ${ }^{4} \cdot$ Tuija Sievänen $^{5} \cdot$ Patrizia Gasparini $^{6}$
}

Received: 26 November 2019 / Accepted: 13 April 2020 / Published online: 30 July 2020

(C) The Author(s) 2020

\begin{abstract}
- Key message National Forest Inventories (NFIs) hold promise for monitoring and valuing of non-productive forest functions, including social and recreational services. European countries use a range of methods to collect social and recreational information within their NFI methodologies. Data collected frequently included general and recreationspecific infrastructure, but innovative approaches are also used to monitor recreational use and social abuse.

- Context Social and recreational indicators are increasingly valued in efforts to measure the non-productive value of forests in Europe. National Forest Inventories (NFIs) can be used to estimate recreational and social usage of forest land at a national level and relate this use to other biophysical, spatial and topographical features. Nonetheless, there is little information concerning the extent.

- Aims The study aims to identify the coverage of social and recreational data present in European NFIs including the types of data recorded as part of the NFI methodologies across European countries. It also aims to examine contrasting methods used to record social and recreational data and present recommendations for ways forward for countries to integrate these into NFI practice.

- Methods A pan-European questionnaire was designed and distributed to 35 counties as part of the EU-funded project Distributed, Integrated and Harmonised Forest Information for Bioeconomy Outlooks (DIABOLO). The questionnaire probed
\end{abstract}

Handling editors: Tuula Packalen and Klemens Schadauer (Guest Editors)

Contributions of the co-authors Conceptualisation: DME, FSJ, AVDJ, BRD, TS, and PG; methodology: MAA, DME, FSJ, AVDJ, BRD, TS, and PG; software: MAA; validation: MAA, DME; formal analysis: MAA, DME; investigation: MAA, DME, FSJ, AVDJ, BRD, TS, and PG; resources: DME, FSJ; data curation: MAA; writing: MAA; writing, review and editing: MAA, DME, FSJ, AVDJ, TS, and PG; visualisation: MAA, DME; supervision: DME, FSJ; project administration: DME, FSJ; funding acquisition: DME, FSJ, TS, and PG.

This article is part of the topical collection on Forest information for bioeconomy outlooks at European level

Electronic supplementary material The online version of this article (https://doi.org/10.1007/s13595-020-00952-2) contains supplementary material, which is available to authorized users.

Mark A. Atkinson

mark.atkinson@forestry.gsi.gov.uk

1 Social and Economic Research Group, Forest Research, Farnham, UK

2 Department of Geosciences and Natural Resource Management, University of Copenhagen, Copenhagen, Denmark

3 Copernicus Institute of Sustainable Development, Utrecht University, 3584 CS Utrecht, The Netherlands
4 Inventory, Forecasting and Operational Support, Forest Research, Edinburgh, UK

5 Bio-economy and Environment, Natural Resources Institute Finland (Luke), Helsinki, Finland

6 Consiglio per la ricerca in agricoltura e l'analisi dell'economia agraria - Centro di Ricerca Foreste e Legno (CREA-Research Centre for Forestry and Wood), P.zza Nicolini, 38123 Trento, Italy 
countries on all social and recreational data that was included within NFIs. Qualitative response data was analysed and recoded to measure the extent of social and recreational data recoded in European NFIs both as a function of the number of variable categories per country and the number of countries recording particular variables.

- Results Thirty-one countries reported at least one social or recreational variable over 12 categories of data. The most frequently recorded variables included ownership, general transport infrastructure and recreation-specific infrastructure. Countries collecting data over many different categories included Switzerland, Great Britain, Czech Republic, Luxemburg and Denmark. - Conclusion The study proposes a specific set of indicators, based upon countries with well-developed social and recreational data in their NFIs, which could be used by other countries, and report on the extent to which these are currently collected across Europe. It discusses results and makes a series of recommendations concerning priorities for the inclusion of social and recreational data in European NFIs.

Keywords Social data $\cdot$ Recreational use $\cdot$ National Forest Inventory $\cdot$ Indicators

\section{Introduction}

Non-productive forest functions have now been established as an essential component of reporting on the state of European forests (SoEF 2015). For example, over the last decade, indicators of biodiversity have increasingly been integrated into the data collection and reporting activities of National Forest Inventories (NFIs) across Europe - an endeavour which has been refined and guided by efforts to harmonise indicators of biodiversity across the continent (Winter et al. 2008) and specifically driven by work conducted under EU COST Action E 43 (Tomppo et al. 2010). This work demonstrated that effective reporting and analysis of non-productive forest services can be undertaken successfully using NFI data which has driven further research in this area. Despite substantial progress made by COST E 43, there is a need for further integration of other non-productive forest functions, including the social and economic dimensions of sustainable forest management into European level NFI reporting (McRoberts et al. 2009; Vidal et al. 2016). It is this integration of new socioeconomic information into European NFIs which concerns the present paper.

NFIs are systematic assessments of forest information, which are undertaken by European countries at regular intervals. They are critical in the estimation of a country's forest cover as well as productive forest services, including timber volume. Although differences in sample plot selection and sizing methodologies for measuring key metrics and volume estimation exist across European countries, NFIs are successfully aggregated across countries to produce reports of forest land area, tree species and timber production (e.g. Verkerk et al. 2015).

Alongside other non-productive services provided by forests, an established and growing interest across European countries is the social and recreational value attached to them. The last State of Europe Forests report, published by the Forest Europe (SoEF 2015), suggests that more than $80 \%$ of forest and other wooded land in Europe is available for recreational purposes, although less than $6 \%$ has recreational use as a main management goal. Whilst such headline figures are illuminating, detailed information on the social and recreational value of forest land across Europe is still elusive. For example, whilst $80 \%$ of forest and wooded land may be available for recreation, this high figure may overestimate the true accessibility of such land due to topography, transport, infrastructure and legal rights. Conversely, whilst only $6 \%$ of land may have recreation as a principle management goal, there may be a much greater proportion of European forest land with high social value in its natural features, heritage and basic infrastructure. It is in these areas that NFIs may be valuable sources of information for supporting a true indicator of social and recreational value in Europe's forests.

The ecosystem service classification proposed by the Millennium Ecosystem Assessment (Alcamo et al. 2003) includes as 'cultural services', recreational, spiritual and other non-material benefits people obtain from ecosystems. These benefits include contributions to health and well-being (Kristensen et al. 2010; Pretty et al. 2007; Cervinka et al. 2014; Karjalainen et al. 2010); connections to landscape and nature (Tuan 1974); education and learning (O'Brien and Murray 2007); and economic benefits (Edwards et al. 2008), social connections (Peters et al. 2010; Seeland et al. 2009) and cultural and spiritual benefits (Hølleland et al. 2017; Williams and Harvey 2001). Efforts have been made to develop indicators of recreational use and social value in forests (e.g. Sievanen et al. 2013; Bryce et al. 2016). Social and recreational indicators are also valuable in forest management and policy in order to assess the influence of ownership, silviculture, biodiversity and accessibility on social and recreational outcomes (Edwards et al. 2012) as well as help managers adapt forest management practices to changes in visitor numbers. Table 1 provides examples for indicators of social and recreational functions of forests. Nonetheless, it 
Table 1 Examples of common indicators of social and recreational forest function

\begin{tabular}{ll}
\hline Indicator & Use as forest Europe pan-European indicator \\
\hline Number of recreational visits & No \\
Area accessible for public recreation & Yes \\
Area managed specifically for recreation & Yes \\
Visitor satisfaction & No \\
Heritage value, e.g. old growth, cultural or spiritual features & Yes \\
\hline
\end{tabular}

is recognised that these indicators are limited. For example, direct comparisons between countries are not feasible due to the different data sources, methods of estimation and reference years in the case of Forest Europe PanEuropean Indicator 6.10. Integrating these and other assessments of social and recreational forest functions into NFIs holds the promise of developing consistent methods for estimation across countries.

Where an inventory has indicators concerning recreational use, these data can be used to estimate the extent to which the management approach influences the use of forests for social and recreational purposes. Studies that have investigated this relationship have been limited by methods that do not use nationally representative sample of forest stand areas. For example, Edwards et al. (2012) examined the relationship of stand type and recreational value in four case studies using an expert panel, rather than naturally occurring relationships drawn from forest area data. A further advantage of NFI data in determining social and recreational use is the range of variables that can be collected and mapped simultaneously at the same level. As such, it is possible to develop indicators that may inform both supply and demand for ecosystem services in a particular area. Using the example of forest management activities, NFI variable can be used to model the influence of forest management strategies (e.g. species choice) on recreational, whilst controlling for the influence of proximity to settlement, ease of access and whether a forest stand is under public or private ownership in order to obtain more accurate estimations of on recreational activity. Conversely, national policy interests may require isolating the influence of accessibility, public transport and visitor parking from other forest characteristics such as species and biodiversity to examine barriers to recreational engagement in planning infrastructure.

Whilst NFI indicators of social and recreational use exist at a national level, little information is available for identifying where these are available to build an international perspective. Both within and outside Europe, reporting on the state of forestry across makes limited use of NFI data to assess the status of either cultural and spiritual values or accessibility for recreation (SoEF 2015). As such, NFIs can fail to communicate information most pertinent to these policy priorities (Kleinn 2017). The promise of utilising such data for the purposes of developing indicators of social and recreational use of forests depends to a large degree on the evaluation and description of a common approach to collecting these data across European NFIs.

The objective of the present study was to explore how social and recreational data are collected, analysed and reported across European NFIs. As well as determining had been taken in addition to any impact such decisions have had on policy and management. We analysed differences across the NFIs in implementing the social variables.

\section{Materials and methods}

The NFI responsible institutions in the 44 signatory countries of Forest Europe with the presence of variables across a range of categories, we investigated the use of social and recreational data in official NFI analysis and reporting, and the historical context in which decisions to include these data in NFI surveys forest cover were contacted for information during March-June 2017. An online questionnaire was developed to collect qualitative data about social and recreational variables across the respondent country NFIs and was presented in four sections (Atkinson et al. 2020). In section 1, respondents were asked background questions, including contact details, the country for which they were reporting and their professional role. Section 2 asked respondents to record details of relevant social and recreational variables in their country's NFI. This section was completed using an attached spreadsheet, which provided a list of potential variables. For each variable, respondents were asked to record information in five columns. The first column recorded the variable name. In the second column, respondents recorded a description of the variable, including guidance provided to surveyors and any response-coding categories or scoring systems for the variable. The third and fourth columns recorded information about training requirements for surveying the variable and instruments required to do so respectively. Finally, in the fifth column, each variable was coded into one of five possible categories (Recreational infrastructure, amenities and facilities; Recreational and non-recreational use; Abuse; Cultural sites 
and features; Other subcategory; More than one subcategory). The questionnaire provided guidance on relevant variables for each of the categories using examples of each category. If there were no social or recreational variables, the respondent was asked to state this in the spreadsheet.

Section 3 asked respondents to provide information variables relevant to the interpretation and classification of social and recreational data, using the same columns provided in section 2. The fifth column coded these other relevant variables into four possible categories (Land ownership; Spatial and topographical attributes; Other subcategory; More than one subcategory). Guidance was again provided on appropriate variables to include in responses to this section.

Finally, section 4 assessed other relevant characteristics of the NFI sampling and reporting process. Question 1 requested participants to describe the sample methodology of the NFI, including the size of the sampling unit, the methodology used to locate the sample (e.g. remote sensing) and the level and spatial scale at which relevant social data were collected (i.e. the whole sample plot or section/stand) and requested a link to published full descriptions of the NFI methodology. Questions 2-5 were only completed by those measuring social and recreational data. Question 2 probed respondents on any analyses undertaken on social and recreational data and whether such analyses were planned. Question 3 asked whether any indicators had been produced through statistical modelling of social and recreational data. Question 4 requested details of any current reporting of NFI data and how these statistics are published. Question 5 asked when social and recreational data was first introduced to the NFI process within the country, and question 6 probed the factors that led to the uptake of social and recreational variables, including the decision-making process, who was involved in the decision and any impact this decision had on policy and management in the country. Finally, question 7 was an opportunity for respondents to include any further information on social and recreational NFI data.

\section{Results}

\subsection{Response and analysis}

Thirty-five countries returned the questionnaire $(80 \%$ of Forest Europe 2015 countries). Responses were first assessed to identify countries that had reported that social and recreational data were collected as part of NFI surveying. Thirty-one $(88 \%)$ reported at least one social or recreational variable or variable relevant to social and recreational use. The first step to coding the data was to review all questionnaires and record any variable that was reported by the respondent from each country. After identifying the range of variables across all countries, we again reviewed the data and identified categories of information across the questionnaire responses. The categories utilised distinctions between variables in the questionnaire (see 'Materials and methods' section); however, we adopted additional categories, which were used by at least one NFI in their submission, resulting in 12 categories of data. Each variable was then assigned to one of these categories of data. Following this categorisation, the variables within each category were further assigned to subcategories, and the number of variables within each was counted. Figure 1 details the presence of data across each subcategory and the total number of countries who collect each variable, as well as the total number of variable subcategories each country collects. The most commonly reported variables were related to land ownership, followed by roads and paths, and access. Great Britain reported data across all the subcategories and Switzerland reported data from nine of them. Other countries which reported a substantial number of variables across several subcategories included the Czech Republic, Denmark, Luxembourg and Slovenia.

\subsection{Access and recreational infrastructure}

The majority of countries reporting infrastructure that could be used for recreation did so using a general transport variable. Eighteen $(51.4 \%)$ countries in total recorded the presence of roads in their NFI sample plots. These could consist of forest roads used only for forestry activities or public roads. Presence of railway tracks was reported by five (14.3\%) countries; Great Britain, Denmark, Iceland and Switzerland differentiated between paved and unpaved forest tracks. Eight (22.6\%) countries revealed data collection activity concerning recreation-specific transport. Recreation-specific transport is defined as any piece of infrastructure planned for the purposes of recreation and the movement of people and thus includes for example, infrastructure such as hiking, running, mountain bike trails or ski lifts. Access information was recorded by $18(51.4 \%)$ countries, including 12 which recorded details of plot accessibility to a reference feature such as the nearest population centre or road, the edge of the forested area or a car park. Four countries reported reasons for inaccessibility by foot, and additionally, five countries indicated the degree of slope and gradient, pertaining to access by foot. Eight countries identified urban woodlands (any indication reported by a country that the NFI sample unit was in an area defined as urban) as a further indicator that a site was accessible. Finally, 18 (51.4\%) countries recorded the presence of recreational infrastructure. Only Great Britain reported a category for private enterprise infrastructure, which included mountain bike hire facilities or forestbased theme parks. This category pertained to any sample plot that contained part or all of a private enterprise facility. 


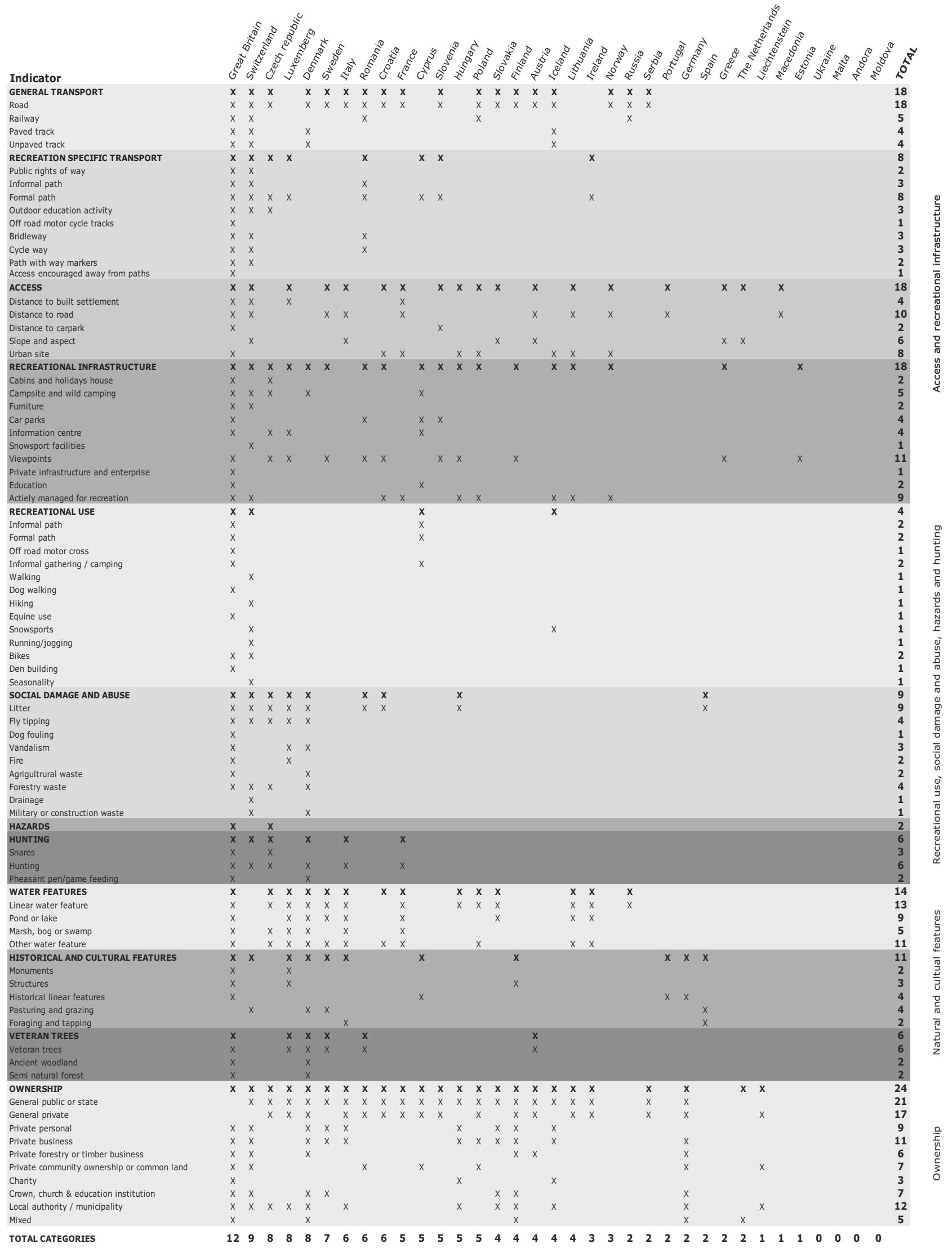

Fig. 1 Number of indicators reported by countries with NFI data relevant to social and recreational use 


\subsection{Recreational use, abuse, hazards and hunting}

Three countries $(8.6 \%)$ recorded evidence of recreational use. In the case of Cyprus, a subset of five out of 65 nature trails was monitored using visitor counters. Numbers of visitors to forest campsites and visitor centres were also recorded. Great Britain utilised an alternative method, where surveyors coded the presence of evidence of recreational use in the sample plot at each stand during surveying. Evidence could take the form of direct observations of recreational activity - such as use of a formal or informal path or dog walking, or could also be recorded indirectly via, for example, cycle tracks or dens built by children. Switzerland did not utilise surveying at inventory sites but instead conducted interviews with staff from forest services. This interview data recorded the level of recreational use, activities undertaken and the seasonality of recreational activity. Switzerland was the only country to collect data on seasonal variations.

Nine (25.7\%) countries reported collecting data on social damage and abuse in survey sites. Of these, seven countries identified whether abuse was recreational or non-recreational in origin (for example, litter or forestry contractor waste). Denmark reported detailed information on abuse, with both recreational and non-recreational abuse, litter, waste and vandalism all recorded, and recreational waste categorised by quantity.

Data on hunting was reported by six (17.1\%) countries, with two reporting the presence of pheasant pens or game feeding, and two countries recording traps or snares. Hunting data was either identified by the presence of such facilities and/or the designation of land use for hunting purposes or the potential for hunting activities or evidence of hunting on the site. The presence of non-natural hazards on the plot was recorded by two $(5.71 \%)$ countries. Great Britain records as hazards anything resulting from social or recreational activity that may affect the health or safety of the surveyor. Great Britain also recorded hazards to surveyors directly resulting from recreation activities. The Czech Republic identified hazards through abuse, with a category for dangerous waste.

\subsection{Natural and cultural features}

Information concerning water features was frequently collected. Linear features such as rivers and streams were identified in 13 NFIs (37.1\%). Other water features were also identified by 11 countries whilst surveying plots, and included river sources, springs, ocean, lakes/ponds, canals and other human built waterways. Water features were identified directly through their presence in sample plots, but in the case of two countries, they were also identified through land use designations. Few countries recorded the presence of historical and cultural features or veteran trees. Foraging potential was specifically identified only by Italy, although this could potentially be inferred from biophysical data that many more countries collect. Spain also recorded evidence of tapping and extraction activities of resin directly in the survey.

\subsection{Ownership}

Land ownership was the most commonly reported variable in the survey. Twenty-four (68.6\%) countries reported data on categories of ownership - most frequently a differentiation between state and private ownership and less frequently, church and local authority and municipality ownership. Ownership data was collected using cadastral, land registry, forest plan or forest district register sources. One country reported that some field checking of recorded ownership categories had been carried out. Switzerland and Great Britain also used questionnaires and/or interviews to collect ownership data.

\subsection{Political context, reporting and analysis, and impact}

Few countries that took part in the survey recorded evidence of impact from the reporting of social and recreational data. Denmark reported that the data has been published as part of official statistics and presented at scientific conferences (e.g. Nord-Larsen et al. 2016). The only country to use NFI data for the creation of indicators and for modelling the relationship between social and biophysical features of forests was Switzerland (Fisher and Fischer and Brändli 2017; Hegetschweiler et al. 2017). No analysis has yet been published by any other.

Respondents reported an interest in developing social and recreational indicators, although responses did not detail specific aspirations. Nonetheless, a number of barriers were reported to developing indicators. These included the number of sampling units being too small to represent social outcomes across the total forest area or the sampling strategy being unsuitable to identify recreation when many sites in the forest area are remote (such that there would be too few data points for robust monitoring of recreational indicators temporally or spatially). In addition, reservations concerning sample plot size being too small to effectively record recreational use were expressed. Finally, a general lack of interest by data users or political decision-makers in obtaining social and recreational information as part of NFI data was identified by some respondents. Countries where recording social and recreational data was a policy interest reported a range of reasons for this. For example, NFIs as tools for decision-making should reflect policy priorities, which have shifted towards the non-market benefits of woodlands for health and well-being, and incomes from recreation can equal or exceed that for timber production 
in some countries. Some respondents also cited Europeanwide reporting obligations, which include recreational use of forests, and inspiration from existing multi-use NFIs, as drivers for the uptake of social and recreational data. Whilst there was evidence of difficulty in integrating social and recreational variables into their existing NFIs, there was interest in the DIABOLO project developing a suitable methodology to achieve this.

\section{Discussion}

There is an increasing drive to develop effective social and recreational indicators of forest land use in Europe (SoEF 2015). Such indicators are vital to understanding a range of non-productive benefits of forestry across the continent. NFIs can make a unique contribution to the development of social and recreational indicators and to our understanding of these benefits in European forests. Despite the promise of NFI data for effective reporting of social and recreational value in European forests, no research has yet provided a systematic overview of the extent to which these data are collected and reported across European NFIs. The present study set out to address this gap by assessing the extent to which social, cultural and recreational information is surveyed in European NFIs and to make recommendations for the development of these processes across the continent.

The present results indicated that social and recreational data were most extensive in the NFIs of Great Britain and Switzerland, with Denmark, Czech Republic, Slovenia and Luxembourg also reporting a high number of relevant variables. These findings confirm previous studies that have identified social indicators as part of NFI data (Sievanen et al. 2013). Reviewing NFIs in these countries allows us to propose examples of social and recreational indicators (Table 2), which are supported by data reported across European NFIs. Below, we make a number of specific recommendations for developing NFIs to include social and recreational variables that could support these indicators.

Indicators of the presence of recreational activity are particularly useful in determining the social value of forests. Only three countries recorded direct evidence of this, and a range of methods were reported for doing this. As a relatively recent addition to any European NFI cycle, further analysis and research concerning methods used to record recreational use is needed to understand their validity. In the case of Great Britain, seasonality, surveyor time on site and weather conditions may all influence the probability of observing recreational use, and the influence of these should be ascertained.

We believe that both surveying on the ground and collecting management data remotely can address the challenge of collecting social data within an NFI. In the case of surveying, it is possible to assess the presence of social activity whilst engaged in general data collection activities. The installation of specialist equipment in addition to the GPS/GIS mapping software used by surveyors to assess forest stand structure will depend upon the methods adopted. For example, some countries reported methods that might require a visitor counter system to be used. Others such as Great Britain record simply presence or absence of recreational use in sample sites using simple observational methods.

Despite these advantages, information on recreational use collected remotely, and through contact with land managers, frequently forms part of NFI activities and can be essential in determining land use priorities and ownership when surveyors cannot ascertain such information on the ground. For remote data, it is possible for more detailed investigations of recreational use to be applied than reported in the present survey. For example, site management visitor surveys may record some basic demographic information such as gender or age, and collecting these data would entail a considerable time commitment and additional training for an NFI surveyor on the ground. Guidance on the best practice for integrating recreational use into NFI methods would be a useful future research direction. In addition, the broader question of to what extent social science methods can really be integrated into these monitoring and estimation exercises (notwithstanding the success of developing methods to monitor biodiversity conservation) and whether there are limits to the desirability for these detailed data warrant future attention in research.

We also recommend that categories used to record features such as buildings, roads, paths and litter should be subdivided to indicate whether or not they are associated with social and recreational use. A pertinent example is the case of transport infrastructure. As noted above, seven countries reported transportation infrastructure specific for recreation with many different categories of infrastructure recorded. However, a bridging category, which can indicate the presence of any road, track or path designated specifically for recreation, could help identify the overall proportion of forest land with recreational transport infrastructure and inform the determinants of any recreational use and abuse in this land.

The results of the present survey show new ways in which NFIs can contribute to new social and recreational information about forests. In particular, countries, which collect data on physical evidence of abuse and social pressure, demonstrate how NFI methods can reveal trends that are more difficult to identify in self-reported visitor engagement surveys, due to subjective response bias. Indeed, in the case of abuse, NFI data may provide more accurate estimates of the scale in which litter and vandalism affect forest areas. NFIs also provide complimentary information for the social and recreational value of forests in the more general case of recreational supply in contrast to visitor engagement surveys, which typically provide data on demand for recreation and social use. Methods to value cultural ecosystem service supply can 
Table 2 Examples of indicators supported by NFI data

\begin{tabular}{ll}
\hline Subcategory & Indicator \\
\hline $\begin{array}{l}\text { Recreational infrastructure, amenities and } \\
\text { facilities }\end{array}$ & Total length of forest roads \\
Recreational and non-recreational use & Total length of formal forest paths \\
Abuse & Percent of forest land with evidence of recreational activity \\
Cultural sites and features & Percent of forest land with evidence of litter \\
& Percent or forest land containing historical sites and \\
& monuments \\
Access & Number of heritage/veteran trees \\
& Percent of accessible forest land \\
& Percent of forest land used for hunting
\end{tabular}

benefit greatly from national estimates of recreational infrastructure, heritage features, accessibility and transport collected by a number of surveyed countries, as this data is frequently unavailable at the scale of small forest areas, or limited to urban municipalities (Tratalos et al. 2016). The variables currently reported by the countries surveyed in this study do not present an exhaustive list of social and recreational data that could be integrated into an NFI. Indeed, a comprehensive policy and research-informed taxonomy of potential variables would be a valuable output from future research in order to inform the design of future NFI cycles.

In the case of inventories that rely heavily on remote sensing and photographic estimation, we can recommend the inclusion of a number of variables relevant to the social and recreational benefits of forests. A number of important variables concerning forest access may be suitable for derivation via remote sensing, for example, informal trails, camping, evidence of abuse and even evidence of recreational use. Such methods have been applied for biodiversity monitoring to identify polygon, linear and point features. Some of these features may also be relevant for social and recreational monitoring including transport routes, enclosures and boundaries (e.g. Ståhl et al. 2011).

A further issue is that, where countries report variables, there may be differences in how they interpret them. For example, definitions of 'old growth' or 'ancient' forest areas can vary nationally. Differences across, and even within, countries about what is a socially valuable forest feature are not merely matters of definition but by nature subjective and specific to a place or group of people (Kangas et al. 2008; Sténs et al. 2016). Finally, a further complication emerges from the varied sampling strategies applied across European countries' NFIs (see Tomppo et al. 2010 for a detailed review). Differences in the sampling of forest areas may have implications for future efforts to harmonise social forestry information and create European-wide indicators, in addition to the general methodology applied to collecting social data. For example, the proportion of forest containing recreational infrastructure (e.g. visitor's centres) will be affected by the size of the sampling area and presence or absence of data points - although methods to computationally correct these scale effects have been reported (e.g. Magnussen et al. 2016). Strategies to develop harmonised indicators from these social data across Europe will have to respond to the challenge of the diversity of NFI methods as well as the diversity of social value more generally. Further detail on the method of recording variables themselves is also critical in future research on social and recreational data in NFI activities. For example, in the case of railways, the present respondents provided little detail on the nature of data collected including whether railway stations or distance to stations were recorded, or how railway lines were mapped onto plots.

At the time of the present study, only Switzerland reported details on the analysis of social and recreational NFI data. For most countries, even where social data was collected, this information is new to the latest cycles of inventorying and has not reached the stage where data is available for reporting or detailed secondary analysis. As such, little impact of these activities on policy- or decision-making can be ascertained across Europe. An important direction for future work is to conduct analyses using the indicators of well-developed European NFIs as case studies, in order to determine whether other social (such as the presence of infrastructure), topographical and biophysical attributes of NFI sample areas predict recreational use. In addition to the direct research value of such analyses, this work will be able to identify what attributes of forest stands are most useful as proxies and indicators of the recreational and social value of forest areas across Europe.

\section{Conclusion}

This study has reported on the extent of social and recreational data collected across NFIs in Europe. We have found that, although social and recreational data is well-developed in some countries, there are still many European countries, which collect little detailed information about social and recreational use of forests or other variables relevant to this use as 
part of NFIs. The information reported by countries where social and recreational assessments are well-developed provides a basis for recommendations, outlined in this paper, for a specific set of indicators and data collection methods, which could be introduced into European NFIs. Finally, we propose that further analysis of data from countries with welldeveloped social and recreational NFI data will provide guidance on the most important attributes of forest land for recreational interest and can be used in a European synthesis of social and recreational use of forests.

Acknowledgements The authors would like to thank the NFI representatives of the thirty-five countries responding to our survey.

Funding information The study was undertaken as part of the project Distributed, Integrated and Harmonised Forest Information for Bioeconomy Outlooks (DIABOLO) and funded by the European Commission Horizon 2020 programme (contract no. 193234).

Data availability The datasets generated during and/or analysed during the current study are available in the Open Science Foundation repository, Atkinson MA, Edwards DM, Jensen F S, van der Jagt APN, Ditchburn, BR, Sievänen, T, Gasparini P (2020) DIABOLO Task 3.2.2. Development and harmonization of social indicators [Dataset]. https://doi.org/10.17605/OSF.IO/DMSQG. Accessed 12 March 2020.

\section{Compliance with ethical standards}

The authors declare that they obtained the informed consent from all participants involved in this study.

Conflict of interest The authors declare that they have no conflict of interest.

Open Access This article is licensed under a Creative Commons Attribution 4.0 International License, which permits use, sharing, adaptation, distribution and reproduction in any medium or format, as long as you give appropriate credit to the original author(s) and the source, provide a link to the Creative Commons licence, and indicate if changes were made. The images or other third party material in this article are included in the article's Creative Commons licence, unless indicated otherwise in a credit line to the material. If material is not included in the article's Creative Commons licence and your intended use is not permitted by statutory regulation or exceeds the permitted use, you will need to obtain permission directly from the copyright holder. To view a copy of this licence, visit http://creativecommons.org/licenses/by/4.0/.

\section{References}

Alcamo J et al (2003) Ecosystems and human well-being: a framework for assessment. Island Press, Washington

Atkinson MA, Edwards DM, Jensen F S, van der Jagt APN, Ditchburn, BR, Sievänen, T, Gasparini P (2020) Harmonising, improving and using social and recreational data in National Forest Inventories across Europe. DIABOLO Task 3.2.2. Development and harmonization of social indicators. V1. Open Science Foundation. [Dataset]. https://doi.org/10.17605/OSF.IO/DMSQG. Accessed 12 March 2020
Bryce R, Irvine KN, Church A, Fish R, Ranger S, Kenter JO (2016) Subjective well-being indicators for large-scale assessment of cultural ecosystem services. Ecosyst Serv 21:258-269. https://doi.org/ 10.1016/jecoser201607015

Cervinka R, Höltge J, Pirgie L, Schwab M, Sudkamp J, Haluza D, Arnberger A, Eder R, Ebenberger M (2014) Green public health benefits of woodlands on human health and well-being. Bundesforschungszentrum für Wald (BFW), Vienna ISBN 978-3902762-32-0

Edwards DM, Jay M, Jensen FS, Lucas B, Marzano M, Montagné C, Peace A, Weiss G (2012) Public preferences across Europe for different forest stand types as sites for recreation. Ecol Soc 17(1). https://doi.org/10.5751/ES-04520-170127

Edwards DM, Morris J, O'Brien L, Sarajev V, Valatin G (2008) The economic and social contribution of forestry for people in Scotland. Forestry Commission Research Note 102. Forestry Commission Scotland, Edinburgh, pp 1-8

Fischer C, Brändli U-B (2017) Zustand Und Entwicklung Siedlungsnaher Wälder - Ergebnisse Aus Dem LFI. Schweizerische Zeitschrift Fur Forstwesen 168(5):252-260. https://doi.org/10.3188/szf20170252

Hegetschweiler KT, Plum C, Fischer C, Brändli U-B, Ginzler C, Hunziker M (2017) Towards a comprehensive social and natural scientific forest-recreation monitoring instrument - a prototypical approach. Landsc Urban Plan 167:84-97

Hølleland H, Skrede J, Holmgaard B (2017) Cultural heritage and ecosystem services: a literature review. Conserv Manag Archaeol Sites 19(3):210-237. https://doi.org/10.1080/1350503320171342069

Kangas A, Haapakoski R, Tyrväinen L (2008) Integrating place-specific social values into forest planning - case of UPM-Kymmene forests in Hyrynsalmi, Finland. Silva Fenn 42:773-790

Karjalainen E, Sarjala T, Raitio H (2010) Promoting human health through forests: overview and major challenges. Environ Health Prev Med 15(1):1-8. https://doi.org/10.1007/s12199-008-0069-2

Kleinn C (2017) The renaissance of National Forest Inventories (NFIs) in the context of the international conventions-a discussion paper on context, background and justification of NFIs. Brazilian J Forest Res 91(37)

Kristensen KH, Jensen FS, Koch E (2010) A review of forest recreation and human health in plantation forests. J Soc Irish Forestry 67(12): $50-123$

McRoberts RE, Tomppo E, Schadauer K, Vidal C, Ståhl G, Chirici G, Lanz A, Cienciala E, Winter S, Smith WB (2009) Harmonizing National Forest Inventories. J For Res 107(4):179-187. https://doi. org/10.1093/jof/107.4.179

Magnussen S, Mandallaz D, Lanz A, Ginzler C, Næsset E, Gobakken T (2016) Scale effects in survey estimates of proportions and quantiles of per unit area attributes. For Ecol Manag 364:122-129

Nord-Larsen T, Johannsen VK, Riis-Nielsen T, Thomsen IM, Suadicani K, Vesterdal L, Gundersen P, Jørgensen BB (2016) Skove og plantager 2015: forest statistics 2015. Københavns Universitet, Institut for Geovidenskab og Naturforvaltning. isbn:978-87-7903751-9

O'Brien L, Murray R (2007) Forest School and its impacts on young children: case studies in Britain. Urban Forestry Urban Green 6(4): 249-265. https://doi.org/10.1016/jufug200703006

Peters K, Elands B, Buijs A (2010) Social interactions in urban parks: stimulating social cohesion? Urban Forestry Urban Green 9(2):93100. https://doi.org/10.1016/jufug200911003

Pretty J, Peacock J, Hine R, Sellens M, South N, Griffin M (2007) Green exercise in the UK countryside: effects on health and psychological well-being, and implications for policy and planning. J Environ Plan Manag 50(2):211-231.https://doi.org/10.1080/ 09640560601156466

Seeland K, Dübendorfer S, Hansmann R (2009) Making friends in Zurich's urban forests and parks: the role of public green space for 
social inclusion of youths from different cultures. Forest Policy Econ 11(1):10-17. https://doi.org/10.1016/jforpol200807005

Sievanen T, Edwards D, Fredman P, Jensen FS, Vistad OI (2013) Social indicators in the forest sector in northern Europe: a review focusing on nature-based recreation and tourism. TemaNord 584:135. https:// doi.org/10.6027/TN2013-584

Ståhl G, Allard A, Esseen PA, Glimskär A, Ringvall A, Svensson J, Sundquist S, Christensen P, Torell ÅG, Högström M, Lagerqvist K (2011) National Inventory of Landscapes in Sweden (NILS) scope, design, and experiences from establishing a multiscale biodiversity monitoring system. Environ Monit Assess 173(1-4):579 595

State of Europe's Forests (2015) Status and trends in sustainable forest management in Europe. http://foresteurope.org/state-europesforests-2015-report/. Accessed 10 Oct 2018

Sténs A, Bjärstig T, Nordström E-M, Sandström C, Fries C, Johansson J (2016) In the eye of the stakeholder: the challenges of governing social forest values. Ambio 45(Suppl 2):87

Tomppo E, Gschwantner T, Lawrence M, McRoberts RE (eds) (2010) National forest inventories. Pathways for common reporting. Springer Heidelberg, Dordrecht
Tratalos JA, Haines-Young R, Potschin M, Fish R, Church A (2016) Cultural ecosystem services in the UK: lessons on designing indicators to inform management and policy. Ecol Indic 61:63-73

Tuan, Y. F. (1990). Topophilia: A study of environmental perceptions, attitudes, and values. Columbia University Press.

Verkerk PJ, Levers C, Kuemmerle T, Lindner M, Valbuena R, Verburg PH, Zudin S (2015) Mapping wood production in European forests. For Ecol Manag 357:228-238

Vidal C, Alberdi I, Redmond J, Vestman M, Lanz A, Schadauer K (2016) The role of European National Forest Inventories for international forestry reporting. Ann For Sci 73 (4):793-806

Williams KJH, Harvey D (2001) Transcendent experience in forest environments. J Environ Psychol 21(3):249-260. https://doi.org/10. 1006/jevp20010204

Winter S, Chirici G, McRoberts RE, Hauk E, Tomppo E (2008) Possibilities for harmonizing national forest inventory data for use in forest biodiversity assessments. Forestry $81(1): 33-44$. https://doi. org/10.1093/forestry/cpm042

Publisher's note Springer Nature remains neutral with regard to jurisdictional claims in published maps and institutional affiliations. 